\title{
La reciente reforma de la Constitución Francesa
}

\section{The recent reform of the French Constitution}

Pablo Luis Manili*

http://dx.doi.org/10.21503/lex.v11i12.24

* Profesor de Derecho Constitucional en la Universidad de Buenos Aires (www. pablomanili.com.ar). Una versión anterior de este trabajo se publicó en La Ley (Buenos Aires, Argentina), 2008-E: 1006. 



\section{RESUMEN}

El presente trabajo nos informa acerca de las últimas modificaciones introducidas en la Constitución Francesa respecto de temas por demás importantes, como son los referidos a la reelección presidencial, el referéndum y el control de institucionalidad, entre otros, que son también los mismos que atañen a no pocos países de nuestro continente. Por ello, resulta de especial interés para los estudiosos del Derecho comparado, sobre todo si se considera que la legislación francesa es una de las más importantes dentro de la tradición jurídica occidental.

Palabras clave: Constitución Francesa, Derecho Constitucional.

\section{ABSTRACT}

This work informs us about the latest amendments to the French Constitution on issues for other important, such as those related to presidential reelection, referendum and institutionalism control, among others, which are also the same regarding a few countries in our continent. Thereby, it is of special interest to students of comparative law, especially when it is considered that French law is one of the most important in the Western legal tradition.

Key words: French Constitution, Constitutional Law. 



\section{La influencia francesa en el Derecho Constitucional de Occidente}

Es sabido que Francia es la cuna de las libertades públicas. La Declaración de Derechos del Hombre y del Ciudadano del 26 de agosto de 1789 implica una bisagra en la historia del mundo y muy especialmente del mundo jurídico.

Los revolucionarios franceses adoptaron esa declaración y proclamaron los ideales de libertad, igualdad y fraternidad con una visión cosmopolita de la que carecieron, por ejemplo, los constituyentes norteamericanos, con quienes comparten el honor de ser los iniciadores de la era constitucional. Ese documento, redactado principalmente por Robespierre y el abate Siéyès, ${ }^{1}$ constituyó la piedra fundamental del principio de universalidad de los derechos humanos y un antecedente mediato de la Declaración Universal de los Derechos del Hombre de 1948. Ya su título contiene una toma de postura, al distinguir entre el carácter de persona humana y el de ciudadano, lo cual implica afirmar que el hombre posee derechos por el solo hecho de haber nacido ${ }^{2}$ e independientemente de su condición de ciudadano de un país determinado, lo cual revela una tendencia a la universalidad en materia de derechos humanos, en cuanto se tienen ciertos derechos por ser hombre y otros más por ser ciudadano.

Resultan categóricas las siguientes expresiones de la declaración francesa: "Los representantes del pueblo francés, constituidos en Asamblea Nacional, considerando que la ignorancia, el olvido o el desprecio de los derechos del hombre son las únicas causas de los males públicos y de la corrupción de los gobiernos, han resuelto exponer en una declaración solemne los derechos naturales, inalienables y sagrados del hombre..." (Preámbulo).

Es preciso destacar que la referida declaración se encuentra aún vigente en la Quinta República Francesa, por expresa remisión del Preámbulo de la Constitución de 1958, integrando junto con esta y con el Preámbulo de la Constitución de 1946, lo que la doctrina y jurisprudencia francesas denominan el bloque de constitucionalidad. ${ }^{3}$

1 Cfr. Albert Soboul. La Révolution Francaise. Paris: Presses Universitaires de France (Colección 'Que sais-je?'), 1972, pp. 41 y ss.; y Jean Morange. La Déclaration des Droits de L'Homme et du citoyen, en la misma colección, 1988.

2 Bernard Groethuysen. Filosofía de la Revolución Francesa. Trad. de Carlota Valée. México: Fondo de Cultura Económica, 1989, p. 193.

3 Cfr. Louis Favoreu y Francisco Rubio Llorente. El bloque de la constitucionalidad. Madrid: Civitas, 1991. Para mayor 
El acervo ideológico de la Declaración ha influido notablemente en todo el mundo Occidental, y encontramos rasgos evidentemente inspirados en ella en todas las constituciones dictadas durante el siglo siguiente en Europa y en América. Lamentablemente, solo los derechos en ella consagrados fueron tomados como modelo por las constituciones del siglo siguiente, mientras que no tuvieron la misma suerte los principios rectores taxativamente enunciados: libertad, igualdad y fraternidad, que tiñeron de una ideología solidaria a los derechos consagrados por la declaración francesa, perdurando con toda su fuerza únicamente el de libertad y desdibujándose los otros dos en el marco de la filosofía individualista ${ }^{4}$ que reinó durante el siglo XIX. La era del constitucionalismo clásico o liberal se caracterizó justamente por su individualismo. Ejemplos de este período son las constituciones de la inmensa mayoría de los países de Latinoamérica, que habían conseguido su independencia en las primeras décadas del siglo XIX, como la Constitución Argentina de 1853, en las cuales se consagran los derechos de la persona humana como si fuera un ser aislado, solitario y como si no estuviera inmersa en un complejo tramado social en el que casi ningún derecho puede ser considerado absoluto, a riesgo de que la propia amplitud impida la convivencia.

Con esa base, es obvio concluir que el estudio de la reciente reforma a la Constitución Francesa no tiene solamente interés académico desde la óptica del Derecho comparado, sino que su análisis es ilustrativo para la interpretación de las nuevas tendencias del Derecho Constitucional universal.

\section{La reforma del 23 de julio de 2008}

En esa fecha quedó sancionada la ley constitucional No 724 que modifica la Constitución Francesa en los términos del art. 89 de ese cuerpo normativo.

El mecanismo de reforma no prevé la reunión de una asamblea ad hoc, como en el caso argentino, sino que es llevada a cabo por los órganos constituidos y ordinarios, de acuerdo a ciertos procesos especiales, diferenciados de los que se siguen para la adopción de la legislación común.

Existen dos caminos para reformar la constitución: a) La Revisión Normal, que consiste en la sanción de una ley, que puede ser iniciada por el Presidente o por cualquiera de las cámaras del Parlamento (la Asamblea Nacional y el Senado), debe ser aprobada por las dos y luego sometida a un referéndum popular ratificatorio; o b) La Revisión Abreviada, en la cual, la misma ley, en vez de ser sometida a referéndum, se somete a una asamblea parlamentaria

desarrollo puede verse nuestro libro El bloque de constitucionalidad. La recepción del Derecho Internacional de los Derechos Humanos en el Derecho Constitucional Argentino. Buenos Aires: La Ley, 2003, pp. 283 y ss.

4 Conf. Andrew Reck. "Philosophy in the Debates at the United States Constitutional Convention of 1787", en la obra colectiva Constitutionalism. The Filosophical Dimension. Editada por Alan S. Rosembaum. New York: Grenwood Press, 1988, pp. 113 y ss. 
(es decir, ambas cámaras en conjunto) que debe aprobarla por los tres quintos de los votos emitidos. La convocatoria o no al referéndum ratificatorio determina lo que la doctrina francesa destaca como una tensión entre legitimidad y eficacia. ${ }^{5}$ Incluso, muchos autores sostienen que este segundo método es demasiado favorable a las pretensiones del presidente. ${ }^{6}$

El método aplicado en esta oportunidad fue el segundo, es decir, el abreviado. El trámite del presente proyecto fue relativamente breve (dos meses), ya que su tratamiento fue discutido en la Asamblea Nacional entre el 20 y el 29 de mayo; en el Senado fue tratado entre los días 17 al 24 de junio. En atención a las modificaciones introducidas por el Senado, fue vuelto a tratar en la Asamblea los días 8 y 9 de julio y en el Senado los días 15 y 16 de ese mes. La asamblea legislativa fue convocada por el Presidente de la República el día 17 y se reunió el 21 del mismo mes, aprobando el proyecto en una sola sesión.

\section{El contenido de la reforma}

Se tata de una reforma amplia, que alcanza la mayor parte de los artículos, de los cuales analizaremos solo los más relevantes:

a) Medidas de acción positiva. A semejanza de lo establecido en los artículos 37 y 75 inciso 23 de nuestra Constitución, al artículo $1^{\circ}$ de la Constitución Francesa se le agregó una cláusula por la cual "La ley favorece el igual acceso de mujeres y hombres a los mandatos electorales y funciones electivas, como así también a las responsabilidades profesionales y sociales". La norma, en su redacción anterior, garantizaba la igualdad ante la ley en forma genérica, lo que en argentina denominamos igualdad formal por oposición a la igualdad real. Se trata, por lo tanto, de "reciclar" el derecho a la igualdad tal como tradicionalmente se lo regulaba en las constituciones, adaptándolo a los nuevos tiempos, como hizo nuestro constituyente en 1994.

b) La reelección presidencial. El art. 6 del texto anterior establecía que el mandato presidencial dura siete años y que una ley orgánica ${ }^{7}$ regularía la aplicación de esa norma. La ley de referencia fue sancionada en 1962 con el No 1292 y establece la edad necesaria para ser presidente (23 años), los avales necesarios para presentarse a la elección (que desde

5 Conf. Guy Carcassone. La Constitution. Paris: Editions du Seuil, 1996, p. 317.

6 Conf. Pierre Pactet. Institutions Politiques. Droit Constitutionnel. 16o édition. Paris: Colin, 1997, p. 508.

Las leyes orgánicas constituyen una categoría especial de leyes, que regulan materias de gran importancia, expresamente consagradas en la Constitución: la que estamos analizando (art. 6), la incompatibilidad entre cargos ejecutivos y legislativos (art. 23), la regulación de las asambleas en lo atinente a su duración, elección de miembros, inmunidades, incompatibilidades, etc. (art. 25), los proyectos de ley de finanzas (art. 47), la organización del propio Consejo (art. 63), el Estatuto de los magistrados (art. 64), el funcionamiento del Consejo Superior de la Magistratura. Luego de adoptadas, son enviadas automáticamente al Consejo Constitucional para un examen previo a su entrada en vigor. Ello les otorga una jerarquía superior a las leyes comunes, y por tal motivo algunos autores las consideran como integrantes del bloque de constitucionalidad (Cfr. Louis Favoreu. "Le Principe de Constitutionnalité: Essai de definition d’apres la jurisprudence du Conseil Constitutionnel”. En la obra colectiva Mélanges Eisenman I. Paris: Cujas, 1975, p. 33. 
1976 son quinientos legisladores, consejeros generales, alcaldes, miembros de las asambleas territoriales de ultramar, etc.), la igualdad de los candidatos para acceder a la publicidad en medios oficiales, las pautas que deben seguir para los gastos de campaña y publicación de sus cuentas, etc. La reforma, sin reducir el septenio, agregó un párrafo por el cual "nadie puede ejercer más de dos mandatos consecutivos". Nade dice, sin embargo, de un tercer mandato no consecutivo, el cual, en ausencia de prohibición, quedaría expedito.

c) El referéndum. La reforma añade al art. 11 anterior la posibilidad de que la consulta popular sea solicitada por iniciativa de una quinta parte de los miembros del Parlamento, sostenida por una décima parte de los electores inscriptos. La iniciativa solo puede contener un proyecto de ley, pero no la derogación de una ley que hubiera estado vigente por menos de un año. La norma delega en una ley orgánica la reglamentación de este nuevo instituto, como ocurre en muchas otras previsiones de la Constitución anterior y de las normas que se incorporaron en esta oportunidad, en que el poder constituyente es delegado al legislador común. $^{8}$

d) Designaciones. La reforma intenta limitar la facultad presidencial de designar funcionarios públicos, establecida en el art. 13, ordenando que una ley orgánica regule cuáles serán los funcionarios para cuya designación se requerirá la opinión previa de una comisión permanente de cada cámara. El Presidente no podrá nombrar funcionarios respecto de los cuales se hubieran emitido votos negativos por más de los tres quintos de los integrantes de esas comisiones. La ley orgánica de referencia deberá tener en cuenta la importancia del cargo en relación con el respeto y la garantía de los derechos y libertades o para la vida económica y social de la nación.

e) Estado de sitio. De acuerdo a los postulados del Derecho Internacional de los derechos humanos, la reforma ha actualizado la norma que rige el estado de sitio (art. 16 de la constitución). En efecto, el art. 4 del Pacto Internacional de Derechos Civiles y Políticos establece como requisito, entre otros, que la suspensión de derechos se realice en la medida “estrictamente limitada a las exigencias de la situación". ${ }^{9}$ En tal sentido, la reforma agregó que, luego de treinta días de vigencia del estado de excepción, ciertos funcionarios podrán acudir al Consejo Constitucional a fin de que este examine si las condiciones que justificaron la

8 Mucho se criticó al constituyente argentino de 1994 por haber delegado en el legislador ordinario el dictado de varias leyes de desarrollo constitucional: art. 36 (ley de ética pública), art. 99 inciso 3 (decretos de necesidad y urgencia), art. 85 (Auditoría General de la Nación), art. 86 (Defensor del Pueblo), etc. Siempre discrepamos con esa crítica, dado que el fenómeno de la delegación del poder constituyente o de su ejercicio incompleto no es nuevo, ni exclusivo de la Argentina, tal como demuestra la Constitución Española de 1978 (donde quedó delegado a las Comunidades Autónomas nada menos que el diseño de su relación con el Estado Nacional) y la reforma a la Constitución Francesa que estamos analizando.

9 El art. 15 de la Convención Europea de Derechos Humanos no es tan explícito y no contiene referencia temporal alguna, mientras que la Convención Americana en su art. 27 realiza una pormenorizada regulación del tema. 
declaración aún permanecen vigentes. La sentencia debe ser rápida y pública. Los funcionarios que pueden pedirlo son: el Presidente de la Asamblea Nacional, el Presidente del Senado, sesenta diputados o sesenta senadores. Cuando hubieran transcurrido sesenta días desde su implantación, el Consejo procederá de oficio a emitir una opinión al respecto, que también será rápida y pública. Se trata de un interesante mecanismo de control respecto de la facultad de declarar el estado de sitio, máxime teniendo en cuenta que su declaración está a cargo no del Parlamento sino del Presidente, previa consulta al Primer Ministro, a los presidentes de las asambleas nacionales y al Consejo Constitucional.

Cantidad de legisladores. La reforma agrega un párrafo al art. 24 en el cual se incluye un tope máximo de integrantes del Parlamento: 577 diputados y 348 senadores, lo cual estaba ausente en la anterior redacción. Como se sabe, en Francia cada legislador es elegido en circunscripciones uninominales, a doble vuelta: si un candidato obtiene, en primera vuelta, más de la mitad de los sufragios, será electo automáticamente, pero si no llega a esa cantidad, concurren a la segunda vuelta todos los candidatos que hubieran obtenido más del 12,5\% de los votos. Ello, como se advierte, limita el acceso de partidos políticos pequeños a las bancas parlamentarias.

f) Otras reformas al funcionamiento del Parlamento. También se modifican los artículos 25, 34, 39, 42, 43, 44, 45, 46, 48, 49, 50, 51 y 52 referidos a los miembros, a las atribuciones, al funcionamiento de esa institución, al procedimiento para la sanción de las leyes, al orden del día de las sesiones, a las manifestaciones que puede hacer el ejecutivo ante las cámaras, a las comisiones parlamentarias, etc. El tratamiento detallado de esas reformas excedería los límites de este trabajo e ingresa en el campo del Derecho parlamentario, por lo cual nos limitamos a mencionarlos.

g) La guerra. El art. 35 anterior era similar a nuestro art. 75 inciso 25 , ya que rezaba: "La declaración de guerra será autorizada por el Parlamento". La reforma agregó dos párrafos que contienen —según nuestra opinión — un adecuado equilibrio entre eficacia y control (eterno dilema del constitucionalismo). El primero establece que el gobierno informará al Parlamento acerca del envío de tropas al exterior, dentro de los tres días de enviadas y precisando cuáles son los objetivos perseguidos. Esa notificación dará lugar a un debate pero no a una votación, lo cual debe ser coordinado, a nuestro entender, con la primera parte de la norma, de lo cual se desprende que el Parlamento vota una sola vez: para autorizar la declaración de guerra, pero no lo hace luego para autorizar la salida de tropas. El segundo párrafo ordena que si la intervención armada excede los cuatro meses de duración, el gobierno debe someter su continuación a la autorización del Parlamento. Es decir que, por un lado, la Constitución se ocupa de darle al ejecutivo una herramienta para solucionar el problema urgente: enviar tropas e inmediatamente informar al legislativo, pero por el otro lado se ocupa de que este controle al ejecutivo cuando dicha intervención es prolongada. No obstante lo equilibrado de 
la regulación bajo análisis, no podemos dejar de lamentar que las constituciones aún deban ocuparse de estos temas y que la paz no sea una realidad en el mundo.

h) Decretos de necesidad y urgencia. El art. 38 de la Constitución establecía una regulación para este tipo de normas, consistente en: a) El ejecutivo debe pedir previa autorización al Parlamento; b) Esa autorización se concede por tiempo limitado, el cual se determinará en la propia ley; c) Los decretos (llamados ordonnances) deben ser adoptados en Consejo de Ministros; d) Esos decretos caducarán si el proyecto de ley de ratificación no es enviado al Parlamento dentro de la fecha fijada por la ley que los había autorizado; e) Vencido el plazo por el cual el Parlamento autorizó al ejecutivo a dictarlos, los decretos solo podrán ser modificados por ley. La reforma agregó un requisito más que completa el punto "d" referido más arriba: la ratificación de los decretos debe ser expresa. El requisito coincide con el art. 82 de la Constitución Argentina y más específicamente con el art. 22 de la Ley No 26.122, que reglamenta el control posterior de este tipo de decretos en nuestro país.

i) El Tribunal de Cuentas. Se crea un nuevo artículo a continuación del 47, con el número "47-2", en el cual se aumentan las funciones de este órgano, agregándole la de información y estableciendo la obligación de que las cuentas que rinden las administraciones públicas deberán ser "regulares y sinceras" y deben expresar cabalmente el estado de su patrimonio y su gestión financiera.

j) El Consejo Constitucional: El art. 56 regula la composición de este interesante órgano, depositario del control de constitucionalidad concentrado de los actos de los demás poderes. Se trata de un órgano político, situado fuera de la estructura del poder judicial, e integrado por los expresidentes de la nación (llamados miembros de derecho) y por nueve miembros (llamados miembros designados) que son electos del siguiente modo: tres de ellos por el Presidente del Senado, tres por el Presidente de la Asamblea Nacional y tres por el Presidente de la República. Cada uno de los miembros designados dura nueve años en su mandato, sin posibilidad de reelección. ${ }^{10}$ El Consejo tiene tres tipos de facultades: (i) Como Autoridad Constitucional (regulada en los artículos 7 a 16 de la Constitución), lleva a cabo la fijación de la fecha de elecciones presidenciales, la recepción de las candidaturas para ese cargo, constata impedimentos para el ejercicio del cargo, etc.; (ii) Como Juez Electoral, recibe reclamos relativos a las listas de candidatos, incompatibilidades en los cargos, se expide sobre la regularidad de elecciones, de los referéndum, etc. (arts. 58, 59 y 60 de la Constitución); (iii) Como Juez Constitucional, ejerce dos tipos de facultades: ${ }^{11}$ juzgamiento de la repartición de competencias entre los órganos de poder y juzgamiento de la constitucionalidad de las normas, pudiendo recaer su control sobre reglamentos de las asambleas, tratados internacionales o leyes ordinarias, pero en todos los casos su intervención era anterior a la puesta en vigencia de la

10 Conf. Pactet, P. Op. cit., p. 472.

11 Pactet. Op. cit., p. 477. 
norma. ${ }^{12}$ Pues bien, la reciente reforma, en consonancia con las modificaciones introducidas en el art. 13 y analizadas más arriba, se remite a esa norma en lo atinente a la designación del Presidente del Consejo (la cual es competencia del Presidente de la República) y agrega que las designaciones realizadas por los presidentes de cada cámara deben ser sometidas a la opinión de la comisión permanente competente en cada una de ellas. De alguna manera, estas reformas atenúan la fuerte concentración de poder que el sistema anterior implicaba para el Presidente de la Nación y para los presidentes de las cámaras.

k) El control de constitucionalidad. Según el art. 61 de la Constitución, antes de la reforma, el Consejo Constitucional ejercía su rol de juez constitucional solo en forma preventiva, es decir. antes de la promulgación de las leyes comunes u orgánicas, o de los reglamentos de las asambleas legislativas o de la ratificación de tratados internacionales. La reforma vino a ampliar la posibilidad de acudir al Consejo para la declaración de inconstitucionalidad de una norma, dado que en el nuevo art. 61.1 se establece la posibilidad de que cuando en el trámite de un proceso judicial se cuestiona la constitucionalidad de una norma, el Consejo de Estado o la Corte de Casación pueden enviar la cuestión al Consejo Constitucional. La reglamentación de esta intervención del Consejo es delegada a una ley orgánica, pero el art. 62 nuevo aclara que la declaración de inconstitucionalidad de una norma vigente será inmediata, salvo que la propia decisión del Consejo establezca una fecha posterior. Con esta reforma, el sistema pasa a funcionar de manera similar al español, que combina el control previo con el posterior. Resta por ver cómo reacciona la doctrina francesa frente a esta modificación, dado que, en general, esta alababa los sistemas preventivos y criticaba la inseguridad jurídica que genera la declaración de inconstitucionalidad de una norma vigente.

1) Consejo Superior de la Magistratura. Si bien se mantiene, en líneas generales, su conformación y funciones, tal como estaban reguladas en el art. 65, se reduce la influencia del Poder Ejecutivo y el Presidente de la República deja de ser Presidente de este órgano.

m) El Consejo Económico y Social añade a su denominación las palabras "y ambiental”, ocupándose también de estos temas (art. 69). Se le agrega la función de evacuar consultas del gobierno respecto de temas financieros que impliquen un plan que excede de un año (art. 70); y se limita su cantidad de miembros a doscientos treinta y tres, dado que el art. 71 anterior delegaba su regulación en una ley orgánica, sin establecer límite alguno.

n) Colectividades territoriales. Se modifican, asimismo, varias normas referidas a estas (arts. 72 y siguientes). Entre ellas creemos digna de destacar la que reconoce la pluralidad lingüística (art. 75-1).

12 Conf. art. 61.2. Para un análisis del funcionamiento del sistema en general, puede verse: Miche Fromont 1. La Justice Constitutionnelle dans le Monde. Paris: Dalloz, 1996, p. 70. 
o) El Defensor de los Derechos. La reforma introduce este órgano de control en el art. 71.1, siguiendo así la corriente iniciada en la Constitución Sueca de 1809, que creó esta figura con el nombre de Justitieombudsman, que actuaba como un delegado parlamentario, pero independiente de dicho órgano. Su función era vigilar e inspeccionar la administración, hacer respetar los derechos y libertades de los ciudadanos y admitir sus reclamaciones, y su designación estaba a cargo del Riksdag (Asamblea Nacional). El nuevo órgano francés debe "velar por el respeto de los derechos y las libertades por parte de los órganos de la administración pública, las colectividades territoriales, los establecimientos públicos y por todo organismo que ejerza funciones de servicio público". Puede acudir a él toda persona que considere lesionados sus derechos por el funcionamiento de un servicio público o de uno de los organismos ya mencionados, y también puede actuar de oficio. Sus atribuciones, modo de intervención y demás pormenores de su fisonomía son delegados por el constituyente a una ley orgánica.

p) El Derecho Comunitario Europeo. En el art. 88.5 se establece un mecanismo para dificultar la aprobación de tratados por los cuales un Estado se incorpore a la Unión Europea o a las Comunidades Europeas. Los proyectos de leyes aprobatorias de esos tratados deberán ser sometidos a referéndum por el Presidente de la República. No obstante, si ambas cámaras del Parlamento así lo autorizan por el voto de las tres quintas partes de sus miembros, se podrá utilizar el procedimiento abreviado, que también se aplica para la reforma constitucional, y al cual nos referimos más arriba (contenido en el art. 89, tercer párrafo). 


\section{REFERENCIAS}

- AA.VV. Mélanges Eisenman I. Paris: Cujas, 1975.

- Carcassone, Guy. La Constitution. Paris: Editions du Seuil, 1996.

- Favoreu, Louis y Rubio Llorente, Francisco. El bloque de la constitucionalidad. Madrid: Civitas, 1991.

- Fromont, Michel. La Justice Constitutionnelle dans le Monde. París: Dalloz, 1996.

- Groethuysen, Bernard. Filosofía de la Revolución Francesa. Trad. de Carlota Valée. México: Fondo de Cultura Económica, 1989.

- Morange, Jean. La Déclaration des Droits de L'Homme et du citoyen. París: Presses Universitaires de France (Colección 'Que sais-je?'), 1988.

- Pactet, Pierre. Institutions Politiques. Droit Constitutionnel. 160 édition. Paris: Colin, 1997.

- Reck, Andrew. "Philosophy in the Debates at the United States Constitutional Convention of 1787”. En: AA.VV. Constitutionalism the Filosophical Dimension. Editada por Alan S. Rosembaum. New York: Grenwood Press, 1988.

- Soboul, Albert. La Révolution Francaise. Paris: Presses Universitaires de France (Colección 'Que sais-je?'), 1972. 